\title{
Knowledge Creation and Diffusion in Regional Collaborative Networks
}

\author{
Rafael H.P. Lima and Luiz C.R. Carpinetti \\ School of Engineering of Sao Carlos, University of Sao Paulo, Brazil \\ 400 Trabalhador Sao Carlense Ave, Sao Carlos-SP 13566-590 \\ \{rhlima, carpinet\}@sc.usp.br
}

\begin{abstract}
Industrial clusters can be seen as a type of collaborative networks with a geographically limited scope, since they are environments where firms can collaborate to improve collective efficiency and form networks for knowledge creation and sharing. This paper reviews some contributions found in the literature concerning knowledge management in industrial clusters and proposes a new knowledge management framework to assist local governance in conducting initiatives aiming at creating and sharing knowledge among firms. The framework is still theoretical and future research is necessary for improvement and validation of its phases.
\end{abstract}

Keywords: Collaborative networks, industrial clusters, knowledge management.

\section{Introduction}

Networks have been a central topic in the operations management field and may emerge in several forms, such as partnerships, strategic alliances, inter-organizational relationships or collaborative arrangements [1]. More specifically, a collaborative network $(\mathrm{CN})$ is a type of network constituted by a variety of entities that collaborate to better achieve common or compatible goals [2]. Following this concept, there is a considerable amount of literature that deals with the formation of collaborative networks in regional clusters. The term industrial cluster is probably the most commonly used to refer to geographic concentrations of firms from a specific economic sector, as well as other entities such as supporting institutions, specialized suppliers and universities [3]. In this sense, regional concentrations of firms can also be seen as environments where collaborative networks are likely to emerge [2]. Recent research on clusters has emphasized the linkages between firms both for material and knowledge exchange, thus viewing the clusters as a multitude of network relationships [4]. Additionally, the topic has drawn special interest from both academia and regional governments, who have proposed and set out policies for regional development [5].

Given the importance of knowledge linkages between networked firms, this paper addresses the issue of knowledge creation and diffusion in collaborative networks that involve firms located in industrial clusters. These are referred to in this paper as regional collaborative networks due to the geographic proximity of the parts involved. The purpose of this paper is to propose a knowledge management (KM) framework to 
assist local governance and CNs in the promotion of initiatives aimed at creating and disseminating knowledge, which may impact positively on the overall network performance and reduce the cognitive distance between the entities taking part in the network.

This paper is organized as follows. Section 2 draws from the literature about knowledge management in industrial clusters to build the theoretical background for the framework proposed in this paper. Section 3 consists of this paper's theoretical contribution by describing the knowledge management framework for CNs formed in industrial clusters and proposing an information and communication (ICT) infrastructure to facilitate the framework operation. Finally, Section 4 discusses the theoretical contribution, its limitations and future research opportunities.

\section{Theoretical Background}

Industrial clusters have drawn interest from several researchers, policy makers and practitioners due to their focus on regional development, which give way to several initiatives and policy interventions aiming at upgrading firms and integrating institutions [6]. Studies on geographical concentrations of firms began in the $19^{\text {th }}$ century with economist Alfred Marshall, who emphasized the external economies obtained by businesses such as skilled workforce, specialized suppliers and training services, and so forth. These benefits tended to emerge naturally due to the concentration of firms from the same industry and required little or none interorganizational collaboration to occur [7].

More recently, the focus has shifted from mere external economies to more complex forms of gaining competitive advantage in clusters. Schmitz and Nadvi [8] argue that companies located in clusters should cooperate through joint actions, which are planned initiatives that enable further benefits and may boost competitive advantages of the firms involved. This goes beyond external economies and may increase the collective efficiency of firms. In light of organizational network literature, joint actions can be viewed as a type of $\mathrm{CN}$ that may emerge in industrial clusters, since they seek to combine common objectives and articulate activities among several entities so that these objectives can be achieved.

In this regard, governance becomes a relevant issue so that joint actions can be coordinated and yield positive outcomes. Gilsing [9] claims that governance in clusters refer to the planning and conduction of joint actions that involve local actors and seek to upgrade the cluster as a whole. In this sense, local governance in regional collaborative networks become crucial in determining the strategic issues that need to be addressed by improvement and upgrading processes.

Some researchers have studied the processes by which governance can upgrade the cluster building on the existing literature on organizational performance management. For example, Sölvell et al. [6] developed the Cluster Initiative Performance Model to assist local governance in determining common objectives and devising management processes for areas such as innovation, training, research and cooperation. Other attempts to put forward frameworks for clusters management have been made by authors as Carpinetti et al. [10] and Meyer-Stamer and Harmes-Liedtke [11]. Nevertheless, these contributions lay focus mainly on management processes and address superficially knowledge creation and diffusion processes. 
In recent years, knowledge management at the cluster level has gained significant attention from researchers by drawing from the literature on organizational knowledge management. One such case is the adoption of Nonaka's [12] knowledge spiral by clusters to devise knowledge management initiatives. According to Nonaka's theory, knowledge is created through conversions between tacit and explicit knowledge, which occur by means of interactions between individuals. The processes of socialization, combination, internalization and externalization are used to explain how knowledge can be converted between its explicit and tacit forms, thus enhancing the organizational knowledge base. Following this theory, Evers et al. [13] argues that clusters may gain competitive advantage primarily through the direct transfer of tacit knowledge between firms.

There seems to be a consensus that knowledge is a fundamental resource in industrial clusters, since they enable innovation and upgrading in local firms. For example, Iammarino and McCann [14] claim that regional clusters that wish to efficiently access and use knowledge should develop processes in three dimensions:

(i) Absorption of new knowledge, technologies and innovations and their adaptation to local needs;

(ii) Diffusion of innovations to strengthen the existing knowledge base;

(iii) Creation of new knowledge, technologies and information.

Moreover, some authors believe that successful innovative companies tend to join innovation networks that allow them to combine knowledge and competencies to offer not only products, but more complete solutions. Bullinger et al. [15] argue that innovation networks require strong links between firms, research labs, suppliers and customers, thus forming a dense network of knowledge sharing. Proximity of all actors in the network becomes fundamental, especially because of the tacit nature of most of the knowledge shared among them.

There are some authors who believe that local governance should play an active role in implementing knowledge management practices. Bocquet and Mothe [16] defined three phases for external knowledge integration in clusters and discuss how local governance should act upon them:

(i) Knowledge identification: local governance should identify sources of knowledge that are relevant for companies in the cluster;

(ii) Knowledge acquisition: the knowledge identified needs to be acquired and made available for local firms;

(iii) Knowledge use: local governance should promote initiatives to stimulate firms towards using and making available the new knowledge acquired.

Finally, the authors argue that these three phases are especially suitable for smaller firms in the cluster, since they may not have the amount of resources and capabilities required to identify relevant sources of knowledge. Thus, initiatives carried out by local governance in any of these three phases may increase the overall level of knowledge in the cluster.

\section{Theoretical Contribution}

As discussed in the previous section, knowledge management in industrial clusters is a topic that still needs to be studied further, though some attempts have already been 
made in the literature. Hence, this paper seeks to build on previous contributions and give a step forward by introducing a more detailed framework to assist local governance in conducting knowledge management initiatives. Section 3.1 describes the knowledge management framework for industrial clusters and Section 3.2 proposes a supporting ICT architecture to facilitate the framework operation.

\subsection{Knowledge Management Framework}

The knowledge management framework for industrial clusters is shown in Figure 1. It tries to build on previous efforts reported in the literature by combining the three phases described by Bocquet and Mothe [16] with the four knowledge creation processes proposed by Nonaka [12]. The contribution phase complements the model by outlining activities through which companies can contribute to the enhancement of the cluster's knowledge base.

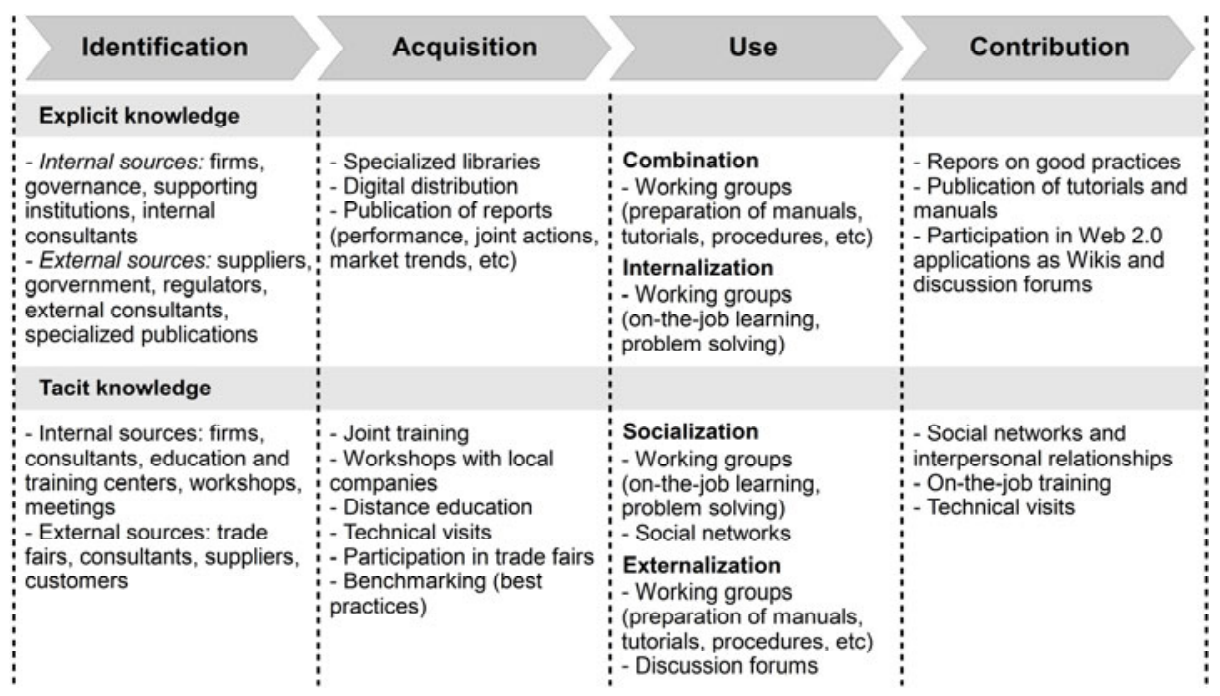

Fig. 1. Phases of the knowledge management framework and the proposed practices for both explicit and tacit knowledge

The framework suggests a set of knowledge sources and practices that can be adopted by local governance in the promotion of knowledge management initiatives. Thus they should be seen more as suggestions than requirements for the framework to function, since each industrial cluster has its own particularities and may tailor the knowledge sources and practices according to its needs. In summary, each of the four phases seeks to answer one specific question:

(i) Identification: what are the relevant internal and external knowledge sources from which local governance can find knowledge of interest to local firms?

(ii) Acquisition: how should local governance acquire and make available the knowledge identified in the previous phase? 
(iii) Use: how should local governance stimulate the use of the knowledge available by local firms in the innovation and improvement of products and processes?

(iv) Contribution: how should local governance and firms share the knowledge they acquired and used, thus contributing to the enhancement of the cluster's knowledge base?

The identification phase seeks to find knowledge sources from which local governance can extract tacit and explicit knowledge. These sources may be available both internally and externally. Many companies, specially the smaller ones, have little ability in finding knowledge sources and determining which of them are relevant [16]. During the acquisition phase, local governance needs to determine how the knowledge sources are to be made available to firms taking part in its initiatives. This can be achieved by means of social channels and the use of ICT.

The use phase refers to the processes by which local governance and firms will use the knowledge acquired to their own needs and consequently create new knowledge. This can be done by applying Nonaka's theory of knowledge creation. The sources made available by local governance may be either tacit or explicit. Moreover they can be used to generate new tacit or explicit knowledge, which is represented by the socialization, internalization, externalization and combination processes. After acquiring and using knowledge, companies and local governance can contribute to the enhancement of the overall cluster knowledge base by sharing the new knowledge they created. This needs not occur with all companies at the same time. Instead, new knowledge may be made available first for partners, suppliers and customers. It is then likely that this knowledge will flow throughout the cluster by other collaboration links, thus eventually covering most of the companies taking part in the governance knowledge management initiatives.

\subsection{ICT Architecture}

Information and communication technologies are reported in the literature as enablers of competitive advantage in collaborative networks, which can be achieved through information sharing and flow among CN participants [17]. As for CNs formed in industrial clusters, some authors have reported on the use of Web 2.0 applications for knowledge creation and sharing [18]. Hence, an ICT architecture constituted by a set of ICT applications can facilitate the operation of the knowledge management framework described in Section 3.1. The use of these technologies should not be seen as a requirement for the framework to function, but instead as a complement or facilitator that will enable local governance to create and diffuse knowledge more efficiently and effectively. Figure 2 shows the proposed ICT architecture, as well as some examples of Web 2.0 applications that can be used to support the operation of the knowledge management framework. The ICT architecture is organized as a knowledge portal in which tacit and explicit knowledge can be stored and shared [19]. It will thus be referred to as the cluster's knowledge portal (CKP).

The CKP is a theoretical ICT architecture that makes use of web technologies to enhance knowledge sharing and interactions between firms in the cluster. The applications and databases should be located in a web server at the local governance 


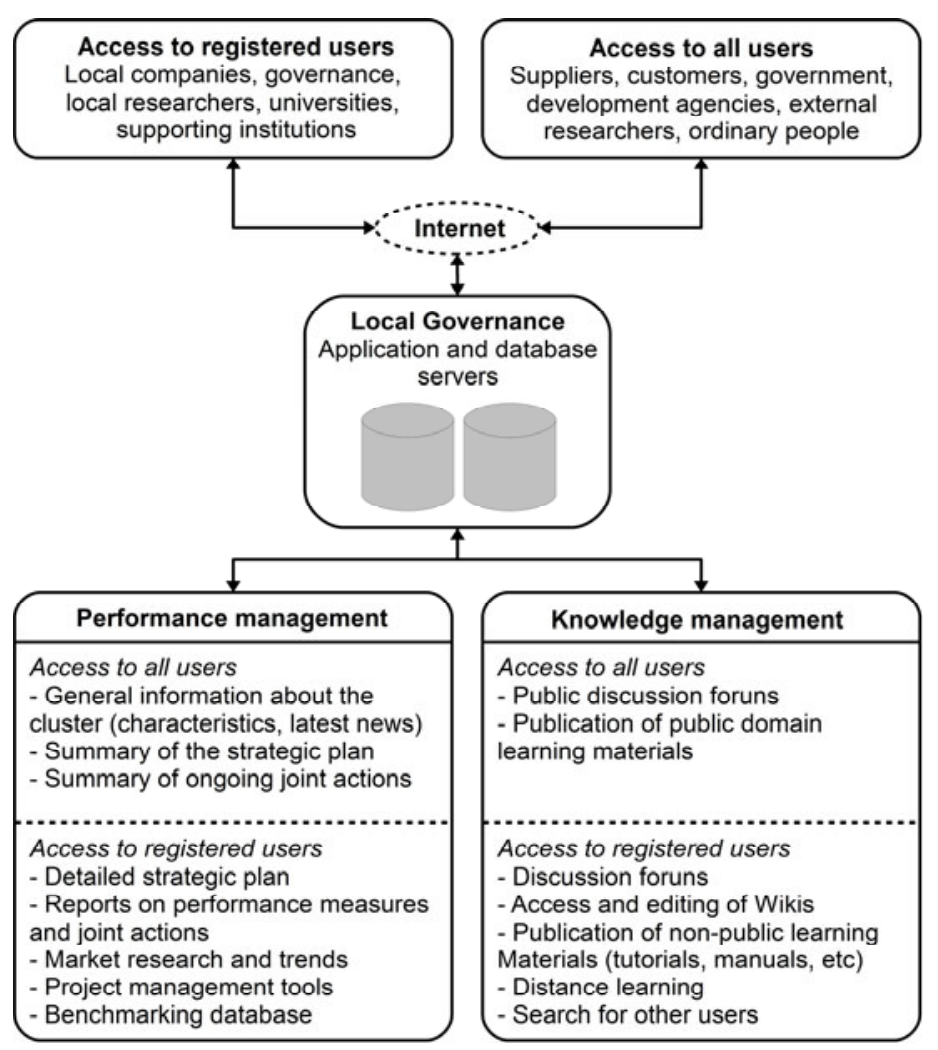

Fig. 2. Set of applications that can be incorporated into the ICT solution to support the implementation of the knowledge management framework for industrial clusters

agency's facilities, in order to avoid conflicts of interest concerning the property of data. The governance agency may manifest as local associations of firms, which implies some level of collaboration and trust among them. Therefore, using the governance agency as the CKP host may increase the likeliness of the applications being effectively used by local firms.

Because the CKP is designed as a web portal and made available using the internet, it becomes necessary to define two levels of access, as depicted in the upper part of Figure 2. Some features should be accessible only to registered users, which are the firms that formally participate in the initiatives promoted by local governance. This requires user account control to restrain access to the applications implemented in the CKP. Users who are not registered to use the CKP applications will only have access to public content that are published as an informative web portal.

As shown in the lower part of Figure 2, the CKP features are divided in two groups. The first group includes a set of performance management features that can be made available for companies to keep track of the cluster's overall objectives, performance measures and ongoing joint actions. The contents of this group are further divided according to their level of access. Hence, general information about 
the cluster is publically available in the CKP, whilst benchmarking and project management tools are accessible only to registered users.

The features included in the second group aim at increasing interactions and knowledge exchange between firms. By means of Web 2.0 technologies, firms can communicate and generate tacit and explicit knowledge, thus increasing the cluster's overall knowledge base. Some features are accessible to all portal visitors, such as public discussion forums and public-domain learning materials. However, most of the features are targeted to firms and other actors from within the cluster. Companies, universities and local governance can work together in the publication of materials and in the stimulation of local actors towards the adoption of these technologies.

\section{Conclusions}

This paper contributes to the field of collaborative networks by proposing a theoretical framework that guides companies and local governance located in regional clusters to implement joint actions aiming at creating and disseminating knowledge. Though the contribution is still theoretical, it builds on previous research reported in the literature and creates a more comprehensive framework that integrates KM practices and information and communication technologies.

Implementing the activities outlined in the $\mathrm{KM}$ framework requires a certain degree of commitment and trust from all the parties involved. Local governance should be an unbiased and independent agent that promotes initiatives that benefit all the firms willing to support such initiatives. Although the framework gives local governance a central role, it is also possible that joint initiatives concerning KM be initiated by other types of actors as local lead-firms or universities.

Following this idea, installing the CKP applications and databases in the governance agency is suitable for clusters in which collaboration is still incipient, which requires interventions from external actors to occur. In an alternate scenario, where a collaborative network and its participants are mature with respect to collaboration and social capital, the CKP and the KM framework could be operated by one of the firms from the network, instead of leaving this role for local governance.

Future research should aim at testing both the KM framework and the CKP empirically to determine their appropriateness and identify areas for improvement. Based on the theoretical contribution herein presented, the authors will carry out a series of case studies in clusters to determine the levels of importance and adoption of each of the activities and technologies outlined in the KM framework and ICT architecture.

\section{References}

1. Provan, K., Fish, A., Sydow, J.: Interorganizational Networks at the Network Level: A Review of the Empirical Literature on Whole Networks. Journal of Management 33, 479516 (2007)

2. Camarinha-Matos, L.M., Afsarmanesh, H.: Collaborative networks: a new scientific discipline. Journal of Intelligent Manufacturing 16, 439-452 (2005) 
3. Porter, M.: Clusters and the new economics of competition. Harvard Business Review, 7790 (November-December 1998)

4. Steiner, M., Ploder, M.: Structure and Strategy within Heterogeneity: Multiple Dimensions of Regional Networking. Regional Studies 42, 793-815 (2008)

5. Enright, M.J.: Regional clusters: what we know and what we should know. In: Bröcker, J., Dohse, D., Soltwedel, R. (eds.) Innovation Clusters and Interregional Competition. Springer, Berlin (2001)

6. Sölvell, O., Lindqvist, G., Ketels, C.: The cluster initiative greenbook. Ivory Tower, Bromma Tryck AB (2003)

7. Marshall, A.: Principles of economics. MacMillan and Co., London (1920)

8. Schmitz, H., Nadvi, K.: Clustering and industrialization: introduction. World Development 27, 1503-1514 (1999)

9. Gilsing, V.: Cluster governance: how clusters can adapt and renew over time. Paper prepared for the DRUID PhD Conference. Erasmus University, Copenhagen (2000)

10. Carpinetti, L., Cardoza, E., Gerolamo, M.: A measurement system for managing performance of industrial clusters: a conceptual model and research cases. International Journal of Productivity and Performance Management 57, 405-419 (2008)

11. Meyer-Stamer, J., Harmes-Liedtke, U.: How to promote clusters. Inter-American Development Bank (2005)

12. Nonaka, I.: A dynamic theory of organizational knowledge creation. Organization Science 5, 14-37 (1994)

13. Evers, H., Gerke, S., Menkhoff, T.: Knowledge clusters and knowledge hubs: designing epistemic landscapes for development. Journal of Knowledge Management 14, 678-689 (2010)

14. Iammarino, S., McCann, P.: The structure and evolution of industrial clusters: transactions, technologies and knowledge spillovers. Research Policy 35, 1018-1036 (2006)

15. Bullinger, H., Auernhammer, K., Gomeringer, A.: Managing innovation networks in the knowledge-driven economy. International Journal of Production Research 42, 3337-3353 (2004)

16. Bocquet, R., Mothe, C.: Knowledge governance within clusters: the case of small firms. Knowledge Management Research \& Practice 8, 229-239 (2010)

17. Chituc, C., Toscano, C., Azevedo, A.: Interoperability in Collaborative Networks: Independent and industry-specific initiatives - The case of the footwear industry. Computers in Industry 59, 741-757 (2008)

18. Adebanjo, D., Michaelides, R.: Analysis of Web 2.0 enabled e-clusters: a case study. Technovation 30, 238-248 (2010)

19. Fernandes, K., Raja, V., Austin, S.: Portals as a knowledge repository and transfer toolVIZCon case study. Technovation 25, 1281-1289 (2005) 